\section{EFSUMB Recently Joined in a Collaboration with the European Society of Radiology (ESR)}

Meetings between the two Societies have already been held in Vienna, both during the WFUMB / EFSUMB Congress and during the congress of ESR. The first combined scientific session will be at the Austria Center in Vienna, during the European Congress of Radiology (ECR) 2013. It will be on Monday, March 11, 2013; 08:30-10:00; Room Z, and will be entitled:

\section{„Advances in diagnostic ultrasound:} better results through cooperation"

$\begin{array}{ll}\begin{array}{l}\text { Introducing the } \\ \text { EFSUMB: the world's } \\ \text { largest } \\ \text { ultrasound Society }\end{array} & \begin{array}{l}\text { N. Gritzmann } \\ \text { (Vienna/AT) }\end{array} \\ \begin{array}{l}\text { ESR/EFSUMB collabora- } \\ \text { tion: a newly establis- } \\ \text { hed platform for joint } \\ \text { development of ultra- } \\ \text { sound in radiology and } \\ \text { clinical specialties }\end{array} & \begin{array}{l}\text { L.E. Derchi } \\ \text { (Genoa/IT) }\end{array} \\ \begin{array}{l}\text { Image fusion and inter- } \\ \text { vention }\end{array} & \begin{array}{l}\text { T. Lorentzen } \\ \text { (Herlev/DK) }\end{array} \\ \begin{array}{l}\text { The EFSUMB non-liver } \\ \text { CEUS guidelines }\end{array} & \begin{array}{l}\text { F. Piscaglia (Bo- } \\ \text { logna/IT) }\end{array} \\ \begin{array}{l}\text { The EFSUMB / WFUMB } \\ \text { liver CEUS guidelines }\end{array} & \begin{array}{l}\text { M. Claudon } \\ \text { (Vandoeuvre- }\end{array} \\ \end{array}$

During the meetings, discussions have been held on a variety of topics. Among them the problem of archiving ultrasound images and reports. From a survey held by the ESR, it has been shown that the ultrasound images (obtained either in radiology or in clinical departments) are not always routinely saved in the hospital PACS systems and that, within the same hospital, the reports of the ultrasound examinations are often recorded in a variety of archives. It has been recognized that it may be difficult to find resources to link all US equipment to the IT hospital system and to provide enough memory to store large amounts of data, especially if video clips need to be recorded. It has also been considered that there may be problems in planning a uniform and complete storage of the examinations' reports, since ultrasound may be used in a large variety of ways, from a stand-alone study to a simple and quick guide to a procedure or a physical exam. However, it has been agreed that availability of ultrasound images and reports for future reference is quite important in clinical practice and it has been decided that both Societies would recommend to their members to organize their ultrasonography workflow so that proper archiving of all examinations performed within each hospital would be regularly obtained.

The main aim of the collaboration between the two Societies is to further promote both clinical and radiological Ultrasound. In the following we want to suggest to our EFSUMB members the advantages of being an ESR member. The European Society of Radiology currently boasts $\mathbf{5 3 , 8 2 2}$ members in good standing from 195 countries. This makes the ESR one of the most important institutions in the field of radiology, aiming to promote radiology and highlight its importance in medicine worldwide.

\section{Education \& Training \\ $\nabla$}

ESR offers a wide range of learning and training opportunities in accordance with its mission to promote diagnostic and interventional radiology and associated disciplines through pre and postgraduate education and research, and to formulate teaching and examination programmes to provide equivalent training for radiologists and other staff working in radiology departments in the relevant countries. ESR has an extensive homepage (http://www.myesr.org) where all the courses can be viewed. In this eLearning has a prominent place.

All ESR members have free and unlimited access to the online version of European Radiology, the official journal of ESR, which in 2010 has reached a Impact Factor of 3.594 and is Europe's no. 1 general radiological journal. The printed version of European Radiology can be purchased by ESR members for only an extra fee. A print subscription includes 12 monthly issues

$4^{\text {th }}$ World Congress of Ultrasound in Medicine and Biology - WFUMB 2013 XVI Congress of the Latin American Federation of Ultrasound - FLAUS 2013 43 ${ }^{\prime \prime 4}$ Sao Paulo Radiological Meeting - JPR'2013 and around 2,500 pages of scientific content.

\section{Research}

Created in order to provide a Europe-wide base for joint research, EIBIR, the European Institute for Biomedical Imaging Research, aims to ensure the pooling of resources among members, to promote a culture of cooperation through networking activities. EIBIR thus wants to generate critical mass and help coordinate research into new instrumentation, methods, concepts and technologies.

\section{Publications \& Media \\ $\nabla$}

Through its various publications in print as well as in electronic format, ESR provides its members and partners with valuable information about and insights into all aspects of radiology-related and society matters. Scientific publications include European Radiology, Insights into Imaging and ESR publications and statements and various ESR and ECR media.

\section{EU Affairs \\ $\nabla$}

The ESR is closely monitoring EU legislation and EU affairs with a potential impact on medical imaging and has started to successfully build relations with relevant EU institutions and EU consulting and public affairs agencies. The ESR needs to be acknowledged as a major stakeholder in EU health policies and involved in consultation processes for new legislative initiatives in this field. In order to achieve this, the ESR has adopted a pro-active approach and has recently established an EU Taskforce.

\section{ECR}

$\nabla$

The annual Congress takes place each year in the beginning of March in Vienna and as a member can be attended at a reduced fee.

Univ. Prof. Dr. Norbert Gritzmann Former President of EFSUMB

Prof. Michael Bachmann Nielsen EFSUMB Publications Committee Chairman 